\title{
Substantiation of Data Files of JEFF-3.1.2 for Safety Analysis of TRIGA Mark-II Reactor through the Scrutiny of Integral Parameter of Benchmark Lattices TRX and BAPL
}

\author{
Md. Mominul Islam ${ }^{1, ~ *, ~ M d . ~ M a h b u b u l ~ H a q u e ², ~ S . ~ M . ~ A z h a r u l ~ I s l a m ³ ~}$ \\ ${ }^{1}$ Department of Physics, Hajee Mohammad Danesh Science \& Technology University, Dinajpur, Bangladesh \\ ${ }^{2}$ Materials Science Division, Atomic Energy Centre Dhaka, Bangladesh Atomic Energy Commission, Dhaka, Bangladesh \\ ${ }^{3}$ Department of Physics, Jahangirnagar University, Savar, Dhaka, Bangladesh
}

Email address:

momin_phyhstu@yahoo.com (Md. M. Islam)

${ }^{*}$ Corresponding author

\section{To cite this article:}

Md. Mominul Islam, Md. Mahbubul Haque, S. M. Azharul Islam. Substantiation of Data Files of JEFF-3.1.2 for Safety Analysis of TRIGA Mark-II Reactor through the Scrutiny of Integral Parameter of Benchmark Lattices TRX and BAPL. American Journal of Modern Physics. Vol. 5, No. 5, 2016, pp. 135-141. doi: 10.11648/j.ajmp.20160505.13

Received: August 4, 2016; Accepted: August 22, 2016; Published: September 10, 2016

\begin{abstract}
The aim of this analysis is to bear out the nuclear data files of JEFF-3.1.2 for theoretical safety analysis of a 3 MW TRIGA MARK-II research reactor is custom-made at AERE, Dhaka, Bangladesh through the study of integral parameters of benchmark lattice TRX and BAPL of thermal reactor. The basic evaluated nuclear data files of JEFF-3.1.2 are selected for TRIGA reactor and processed by using nuclear data processing code NJOY99.0. Different cross-sections of U-235 and U-238 are computed from the NJOY output of the evaluated nuclear data library. The 69 group cross-section library is engendered from the processed file for reactor code WIMSD-5B. From the generated 69 group cross-section library, the integral parameters of yardstick lattices TRX and BAPL are premeditated by using cell code WIMSD-5B. The calculated integral parameters are compared to the deliberated values as well as the consequences of Monte Carlo Code MCNP. From the assessment it is found that all the integral parameters are in good concurrence with some suspicions. Through benchmarking the integral parameters of TRX and BAPL lattices this analysis reflects the support to the evaluated nuclear data files of JEFF3.1.2 for safety analysis of TRIGA Mark-II research reactor at AERE, Dhaka, Bangladesh.
\end{abstract}

Keywords: BAPL, JEFF-3.1.2, NJOY99.0, TRIGA MARK-II, TRX and WIMSD-5B

\section{Introduction}

The Evaluated Nuclear Data Files (ENDF) system was built up for the storage and repossession of evaluated nuclear data to be used for applications of nuclear technology [1]. A vital corollary of each appraisal must be completed for its intended purpose. These applications run many features of the system including the selection of materials to be comprised, the information used, the formats used and the testing is required before a library is released. If the entailed data are not obtainable for various finicky reactions, the evaluator should provide them by using nuclear models [2]. The evaluated data sets are prepared in ENDF format and converted into forms appropriate for testing and actual applications using processing codes. Processing codes that generate point-wise and group averaged cross sections for use in neutronics calculations from an ENDF library are available. The basic data formats for an ENDF library are developed in such a manner that few constraints are placed on using the data as input to the codes that generate any of the secondary libraries [3]. The computer code NJOY99.0 [4] is used for converting nuclear data in ENDF-6 format into libraries as Joint Evaluated Fission and Fusion Data Library (JEFF) in Europe [5], Japanese evaluated nuclear data library (JENDL) [6], Chinese evaluated nuclear data library (CENDL) [7], ENDF/B-VI in USA [8] and BROND in Russia [9]. Joint Evaluated Fission and Fusion Data Library is high quality nuclear data libraries for accessible and prospective nuclear energy systems and this library involves 
evaluation efforts that cover the main nuclear data needs in the fields of fission and fusion applications [10]. The updated version JEFF-3.1.2 which is modified edition of JEFF-3.1.1 [11] is our interest in this present research. To study the safety analysis of Triga Mark -II research reactor by JEFF3.1.2 data library, a careful verification is required for the usable data files of that library. The WIMS code is a freely accessible thermal reactor physics lattice-cell code used widely especially by scientists for thermal research and power reactor applications. In the present work the 69 group cross-section library is generated by using computer program NJOY99.0 and WIMSD-5B [12, 13]. The bench mark lattice TRX and BAPL is used for benchmarking the integral parameter for the generated library. The calculated integral parameters are compared to the standards values.

\section{Methods}

The tools of this study are computer program: NJOY99.0, WIMSD-5B; evaluated nuclear data library: JEFF-3.1.2; benchmark lattices: Thermal Reactor-one region lattice (TRX) and Bettis Atomic Power Laboratory-one region lattice (BAPL).

\subsection{Computer Code NJOY99.0}

The nuclear data processing system NJOY having new version NJOY99.0 is a modular computer code used for data processing in ENDF-6 format. One of the common applications of NJOY99.0 is to generate 69 group crosssection library from basic nuclear data library. The 69 group cross-section library for WIMSD-5B code from basic data files of JEFF-3.1.2 is created by NJOY99.0.

Table 1. Properties of TRX benchmark lattice.

\begin{tabular}{llll}
\hline Segment & $\begin{array}{l}\text { External } \\
\text { radius in cm }\end{array}$ & Nuclei & $\begin{array}{l}\text { Concentration (E 24 } \\
\text { atoms/cm }\end{array}$ \\
\hline \multirow{2}{*}{ Fuel } & 0.4915 & ${ }^{235} \mathrm{U}$ & $6.2530 \mathrm{E}-04$ \\
Void & 0.5042 & ${ }^{238} \mathrm{U}$ & $4.7205 \mathrm{E}-02$ \\
Clad & 0.5753 & -------- & ------ \\
Moderator & $*$ & $\mathrm{Al}$ & $6.025 \mathrm{E}-02$ \\
& & ${ }^{1} \mathrm{H}$ & $6.676 \mathrm{E}-02$ \\
\hline
\end{tabular}

*Lattices spacing are $1.8060 \mathrm{~cm} \& 2.1740 \mathrm{~cm}$ in triangular arrays

Table 2. Properties of BAPL benchmark lattice.

\begin{tabular}{llll}
\hline Segment & $\begin{array}{l}\text { External } \\
\text { radius in cm }\end{array}$ & Nuclei & $\begin{array}{l}\text { Concentration (E 24 } \\
\left.\text { atoms } / \mathbf{c m}^{\mathbf{3}}\right)\end{array}$ \\
\hline \multirow{2}{*}{ Fuel } & 0.4864 & ${ }^{235} \mathrm{U}$ & $3.1120 \mathrm{E}-04$ \\
Void & 0.5042 & ${ }^{238} \mathrm{U}$ & $2.3127 \mathrm{E}-02$ \\
$\mathrm{Clad}$ & 0.5753 & ------ & ---- \\
\multirow{2}{*}{ Moderator } & $* *$ & $\mathrm{Al}$ & $6.025 \mathrm{E}-02$ \\
& & ${ }^{1} \mathrm{H}$ & $6.676 \mathrm{E}-02$ \\
\hline
\end{tabular}

**Lattices spacing are $1.5578 \mathrm{~cm}, 1.6523 \mathrm{~cm}$ and $1.8057 \mathrm{~cm}$
Table 3. Concern isotope of TRIGA with the respective material ID.

\begin{tabular}{lll}
\hline SL. NO. & Isotope & Material ID. \\
\hline 01 & $1-\mathrm{H}-1$ & 125 \\
02 & $5-\mathrm{B}-10$ & 525 \\
03 & $6-\mathrm{C}-12$ & 625 \\
04 & $7-\mathrm{N}-14$ & 725 \\
05 & $8-\mathrm{O}-16$ & 825 \\
06 & $13-\mathrm{Al}-27$ & 1325 \\
07 & $14-\mathrm{Si}-28$ & 1425 \\
08 & $24-\mathrm{Cr}-52$ & 2431 \\
09 & $25-\mathrm{Mn}-55$ & 2525 \\
10 & $26-\mathrm{Fe}-56$ & 2631 \\
11 & $28-\mathrm{Ni}-58$ & 2825 \\
12 & $40-\mathrm{Zr}-91$ & 4028 \\
13 & $68-\mathrm{Er}-166$ & 6837 \\
14 & $68-\mathrm{Er}-167$ & 6840 \\
15 & $82-\mathrm{Pb}-207$ & 8234 \\
16 & $92-\mathrm{U}-235$ & 9228 \\
17 & $92-\mathrm{U}-238$ & 9237 \\
\hline
\end{tabular}

\subsection{Reactor Code WIMSD-5B}

WIMS consisting of a lattice transport code and the associated library WILLIE is used to unravel various thermal reactor problems. The unique WIMSD structure is used with 14 fast group between $10 \mathrm{MeV}$ and $9.11 \mathrm{keV}$; 13 resonance group between $9.118 \mathrm{keV}$ and $4 \mathrm{eV}$; and 42 thermal groups from $4 \mathrm{eV}$ and $0 \mathrm{eV}$ [14]. Rejoinder of U-235 and U-238 is taken to compute the integral parameters of benchmark lattices by using WIMSD-5B code.

\subsection{Benchmark Lattices}

The $\mathrm{H}_{2} \mathrm{O}$ - moderated uranium lattices TRX-1 and TRX-2 [15] and $\mathrm{H}_{2} \mathrm{O}$-moderated uranium oxide critical lattices BAPL-UO ${ }_{2}-1$, BAPL- $\mathrm{UO}_{2}-2$ and BAPL- $\mathrm{UO}_{2}-3$ is used for benchmarking of several integral parameter. BAPL-1, BAPL2 and BAPL-3 used uranium oxide fuel enriched $1.311 \mathrm{wt} \%$; TRX-1, TRX-2 used uranium metal fuel in U-235 enriched to $1.305 \mathrm{wt} \%$. These five lattices are called benchmark lattice. The material and dimensional properties of TRX benchmark lattices are listed in Table-1 [16] and properties of BAPL lattices listed in Table-2 [17]. The interaction of U-235 and $\mathrm{U}-238$ nuclei at $300 \mathrm{~K}$ is used to compute the integral parameter of the benchmark lattices using the reactor code WIMSD-5B. The WIMSD-5B is also used to determine neutron cross-section in thermal as well as epithermal range of U-235 and U-238 isotopes for each benchmark lattices.

\subsection{Calculation Techniques}

The exactness of the processed Group-wise Evaluated Nuclear Data File (GENDF) is analyzed to demonstrate the worth of the previously evaluated data. The chain of NJOY99.0 modules [18], which have been used to generate the 69-group cross section library, is represented by flow chart in Fig.-1. The data strips are routed using NJOY99.0, which can rich the new quality feature of the database. The isotopes listed in Table-2 are concern to the TRIGA Mark-II at AERE, Dhaka, Bangladesh. These elements have been processed in RECONR- BROADR- UNRESR- THERMRGROUPR- WIMSR cycle by Pentium-IV PC in DOS 
command mode [19]. Using the WILLIE and WIMSD-5B code 69-group cross-section library is generated from the processed isotope of JEFF-3.1.2. Fission cross-section, absorption cross-section, captured cross-section of U-235 and $\mathrm{U}-238$ are computed for TRX-1, TRX-2, BAPL-UO ${ }_{2}-1$, BAPL- $\mathrm{UO}_{2}-2$ and $\mathrm{BAPL}-\mathrm{UO}_{2}-3$ lattices through the generated 69-group cross-section libraries of JEFF-3.1.2 by using WIMSD-5B. The integral parameters $\rho^{28}, \delta^{25}, \delta^{28}$ and $C^{*}$ of TRX and BAPL lattices are represented in equations 2 to 5 [20]. The effective multiplication factor is noted by equation 1 . The integral parameter of TRX and BAPL lattices of thermal reactor are calculated using this equation. The evaluated values of the integral parameters have been compared with the experimental values by crosssection evaluated working group (CSEWG) [21]. The overall analysis is performed at the department of Physics, Jahangirnagar University, Bangladesh.

$\mathrm{k}_{\mathrm{eff}}=$ (neutron production from fission in one generation) / (neutron absorption in the preceding generation + neutron leakage in the preceding generation)

$\rho^{28}=$ Ratio of epithermal to thermal neutron captures cross-section of ${ }^{238} \mathrm{U}$

$$
=\left(\Sigma_{\mathrm{c}}\right)^{38}{ }_{\text {epth }} /\left(\Sigma_{\mathrm{c}}\right)^{38}{ }_{\text {th }}=\left(\Sigma_{\mathrm{a}}-\sum_{\mathrm{f}}\right)^{38}{ }_{\text {epth }} /\left(\Sigma_{\mathrm{a}}-\sum_{\mathrm{f}}\right)^{38}{ }_{\text {th }}
$$

$\delta^{25}=$ Ratio of epithermal to thermal neutron fission cross section of ${ }^{235} \mathrm{U}$

$$
=\left(\Sigma_{\mathrm{f}}\right)^{35}{ }_{\text {epth }} /\left(\Sigma_{\mathrm{f}}\right)^{35} \text { th }
$$

$\delta^{28}=$ Ratio of ${ }^{238} \mathrm{U}$ fission to ${ }^{235} \mathrm{U}$ fission

$$
=\left(\Sigma_{\mathrm{f}}^{\mathrm{t}}\right)^{38} /\left(\Sigma_{\mathrm{f}}^{\mathrm{t}}\right)^{35}
$$

$\mathrm{C}^{*}=$ Ratio of ${ }^{238} \mathrm{U}$ captures to ${ }^{235} \mathrm{U}$ fissions

$$
=\left(\Sigma_{\mathrm{c}}^{\mathrm{t}}\right)^{38} /\left(\Sigma_{\mathrm{f}}^{\mathrm{t}}\right)^{35}=\left(\Sigma_{\mathrm{a}}^{\mathrm{t}}-\Sigma_{\mathrm{f}}^{\mathrm{t}}\right) 38 /\left(\Sigma_{\mathrm{f}}^{\mathrm{t}}\right)^{35}
$$

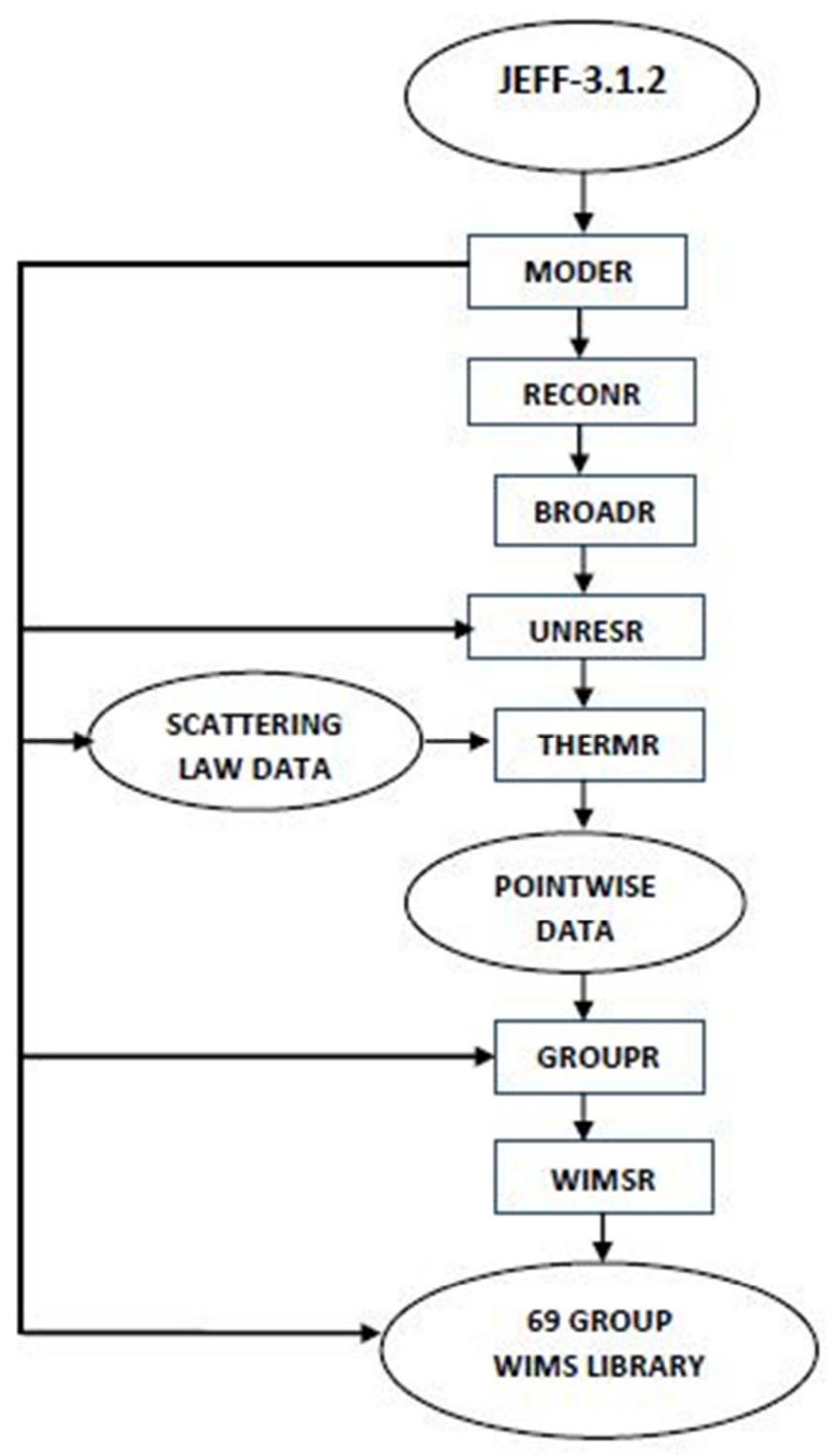

Figure 1. Flow chart of nuclear data processing code NJOY99.0. 


\section{Results}

The NJOY output of the two isotopes U-235 and U-238 are compared in Tables 4 to 5 within the thermal range. The calculated epithermal absorption cross section, thermal absorption cross section, total absorption cross section, epithermal fission cross section, thermal fission cross section, epithermal capture cross section and total fission cross section for neutrons on U-235 and U-238 of benchmark lattices TRX and BAPL are plotted in Figs. 2 to 6 . The values of effective multiplication factor $k_{\text {eff }}$ for TRX and BAPL lattices are calculated and listed in Tables $6 \& 7$. The calculated values of other integral parameters $\rho^{28}, \delta^{25}$, $\delta^{28}$ and $\mathrm{C}^{*}$ for TRX and BAPL lattices are summarized in Tables $8 \& 9$ and compared with experimental values by CSEWG.

In the horizontal axes of graphs from Figs. 2 to Fig. 6, the symbols a, b, c, d, e, f and g represent epithermal absorption cross-section, thermal absorption cross-section, total absorption cross section, epithermal fission cross-section, thermal fission cross-section, epithermal capture crosssection and total fission cross-section, respectively.

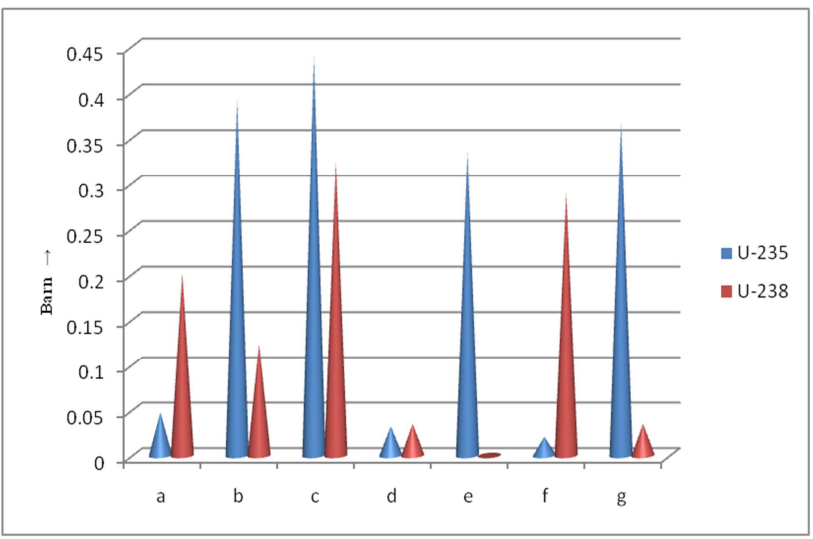

Figure 2. Cross-section of U-235 \& U-238 for TRX-1 lattice.

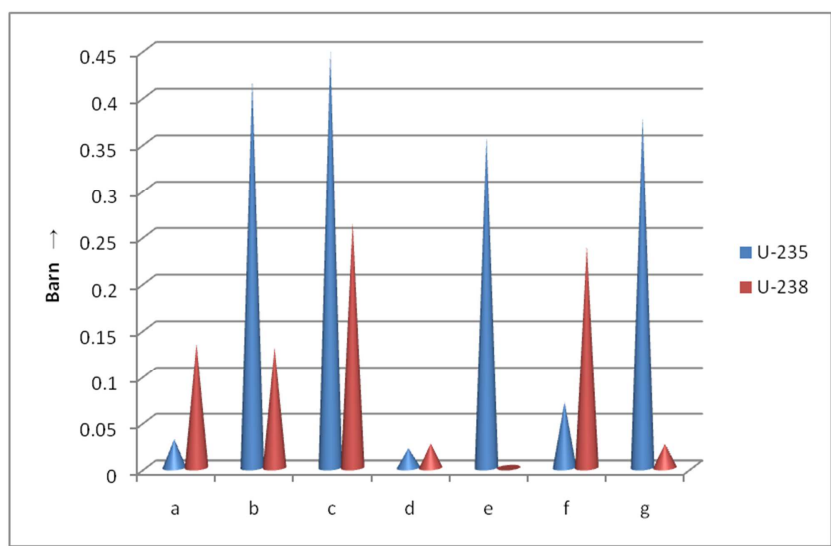

Figure 3. Cross-section of U-235 \& U-238 for TRX-2 lattice.
Table 4. Absorption \& Fission cross-section from NJOY out of U-235 \& U238 in JEFF-3.1.2.

\begin{tabular}{|c|c|c|c|c|c|}
\hline \multirow{2}{*}{$\begin{array}{l}\text { Energy } \\
\text { group } \\
\text { no. }\end{array}$} & \multirow{2}{*}{$\begin{array}{l}\text { Thermal } \\
\text { energy } \\
(\mathrm{eV})\end{array}$} & \multicolumn{2}{|c|}{$\begin{array}{l}\text { Absorption cross- } \\
\text { section in barn }\end{array}$} & \multicolumn{2}{|c|}{$\begin{array}{l}\text { Fission cross-section } \\
\text { in barn }\end{array}$} \\
\hline & & U-235 & U-238 & U-235 & U-238 \\
\hline 28 & 4.000 & 43.533 & 0.64026 & 26.933 & $3.1331 \mathrm{E}-06$ \\
\hline 29 & 3.300 & 30.120 & 0.51490 & 23.401 & $3.1620 \mathrm{E}-06$ \\
\hline 30 & 2.600 & 14.579 & 0.46582 & 11.295 & $3.1373 \mathrm{E}-06$ \\
\hline 31 & 2.100 & 26.410 & 0.45476 & 15.919 & $3.6127 \mathrm{E}-06$ \\
\hline 32 & 1.500 & 24.804 & 0.46632 & 19.098 & $3.9454 \mathrm{E}-06$ \\
\hline 33 & 1.300 & 73.260 & 0.47913 & 53.315 & 4.1586E-06 \\
\hline 34 & 1.150 & 136.64 & 0.48902 & 106.58 & $4.2940 \mathrm{E}-06$ \\
\hline 35 & 1.123 & 113.36 & 0.49210 & 105.38 & 4.3363E-06 \\
\hline 36 & 1.097 & 116.77 & 0.49512 & 96.053 & $4.3779 \mathrm{E}-06$ \\
\hline 37 & 1.071 & 101.49 & 0.49814 & 85.271 & 4.4194E-06 \\
\hline 38 & 1.045 & 89.239 & 0.50110 & 76.214 & $4.4601 \mathrm{E}-06$ \\
\hline 39 & 1.020 & 80.565 & 0.50397 & 69.443 & 4.4995E-06 \\
\hline 40 & 0.996 & 74.315 & 0.50766 & 64.841 & $4.5463 \mathrm{E}-06$ \\
\hline 41 & 0.972 & 69.948 & 0.51165 & 61.456 & 4.5954E-06 \\
\hline 42 & 0.950 & 66.089 & 0.51704 & 58.452 & $4.6618 \mathrm{E}-06$ \\
\hline 43 & 0.910 & 62.608 & 0.52605 & 55.765 & 4.7719E-06 \\
\hline 44 & 0.850 & 61.428 & 0.54052 & 54.969 & $4.9416 \mathrm{E}-06$ \\
\hline 45 & 0.780 & 65.862 & 0.57150 & 58.980 & $5.2942 \mathrm{E}-06$ \\
\hline 46 & 0.625 & 81.247 & 0.62384 & 72.252 & $5.8672 \mathrm{E}-06$ \\
\hline 47 & 0.500 & 111.78 & 0.68368 & 97.674 & $6.5038 \mathrm{E}-06$ \\
\hline 48 & 0.400 & 156.80 & 0.73736 & 133.49 & 7.0642E-06 \\
\hline 49 & 0.350 & 198.13 & 0.77403 & 164.84 & 7.4432E-06 \\
\hline 50 & 0.320 & 225.07 & 0.80114 & 184.35 & $7.7218 \mathrm{E}-06$ \\
\hline 51 & 0.300 & 238.33 & 0.82589 & 193.20 & $7.7752 \mathrm{E}-06$ \\
\hline 52 & 0.280 & 236.98 & 0.68145 & 191.04 & $8.3380 \mathrm{E}-06$ \\
\hline 53 & 0.250 & 222.38 & 0.91109 & 180.28 & $8.8425-06$ \\
\hline 54 & 0.220 & 212.86 & 0.98454 & 175.58 & $9.8585 \mathrm{E}-06$ \\
\hline 55 & 0.180 & 224.93 & 1.0985 & 189.27 & $1.0707 \mathrm{E}-05$ \\
\hline 56 & 0.140 & 264.47 & 1.2605 & 225.68 & $1.2358 \mathrm{E}-05$ \\
\hline 57 & 0.100 & 315.69 & 1.4407 & 271.11 & $1.4159 \mathrm{E}-05$ \\
\hline 58 & 0.080 & 359.60 & 1.5890 & 309.48 & $1.5637 \mathrm{E}-05$ \\
\hline 59 & 0.067 & 398.60 & 1.7189 & 343.13 & $1.6930 \mathrm{E}-05$ \\
\hline 60 & 0.058 & 437.03 & 1.8462 & 376.44 & $1.8196 \mathrm{E}-05$ \\
\hline 61 & 0.050 & 482.50 & 1.9984 & 415.38 & $1.9709 \mathrm{E}-05$ \\
\hline 62 & 0.042 & 536.91 & 2.1822 & 461.67 & $2.1536 \mathrm{E}-05$ \\
\hline 63 & 0.035 & 592.86 & 2.3730 & 508.92 & $2.3430 \mathrm{E}-05$ \\
\hline 64 & 0.030 & 652.42 & 2.5769 & 558.88 & $2.5453 \mathrm{E}-05$ \\
\hline 65 & 0.025 & 730.59 & 2.8459 & 624.01 & $2.8121 \mathrm{E}-05$ \\
\hline 66 & 0.020 & 839.86 & 3.2255 & 714.61 & $3.1885 \mathrm{E}-05$ \\
\hline 67 & 0.015 & 1007.7 & 3.8121 & 853.53 & $3.7699 \mathrm{E}-05$ \\
\hline 68 & 0.010 & 1318.1 & 4.9044 & 111.15 & $4.8481 \mathrm{E}-05$ \\
\hline 69 & 0.005 & 221.59 & 8.0839 & 1863.2 & $8.0005 \mathrm{E}-05$ \\
\hline
\end{tabular}

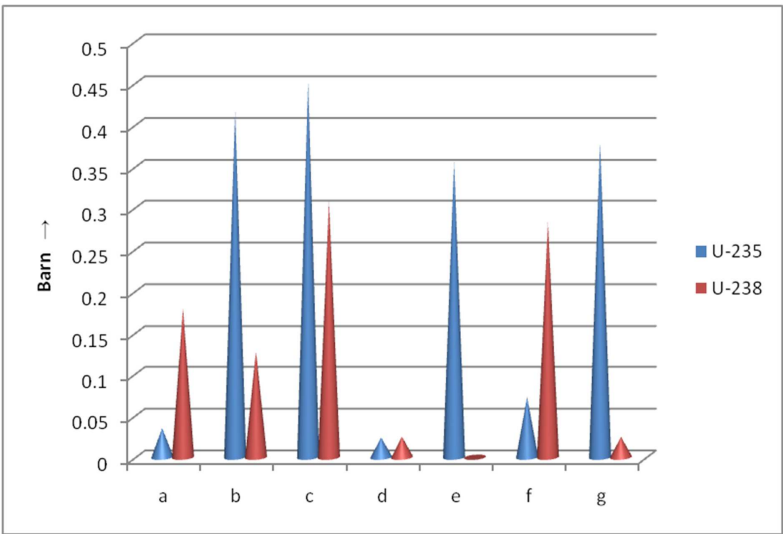

Figure 4. Cross-section of U-235 \& U-238 for BAPL-.1. 
Table 5. Transport \& total scattering cross-section from NJOY out of U-235 \& $U-238$ in JEFF-3.1.2.

\begin{tabular}{|c|c|c|c|c|c|}
\hline \multirow{2}{*}{$\begin{array}{l}\text { Energy } \\
\text { group no. }\end{array}$} & \multirow{2}{*}{$\begin{array}{l}\text { Thermal } \\
\text { energy }(\mathrm{eV})\end{array}$} & \multicolumn{2}{|c|}{$\begin{array}{l}\text { Transport cross- } \\
\text { section in barns }\end{array}$} & \multicolumn{2}{|c|}{$\begin{array}{l}\text { Total scattering } \\
\text { cross-section barn }\end{array}$} \\
\hline & & U-235 & U-238 & U-235 & U-238 \\
\hline 28 & 4.000 & 55.107 & 9.1126 & 10.970 & 8.0167 \\
\hline 29 & 3.300 & 41.786 & 9.2503 & 11.066 & 8.2884 \\
\hline 30 & 2.600 & 26.642 & 9.3123 & 11.319 & 8.3011 \\
\hline 31 & 2.100 & 38.782 & 9.4295 & 11.839 & 8.5922 \\
\hline 32 & 1.500 & 37.621 & 9.5217 & 11.405 & 8.0688 \\
\hline 33 & 1.300 & 86.391 & 9.5762 & 11.381 & 7.8842 \\
\hline 34 & 1.150 & 149.68 & 9.6143 & 5.6979 & 3.9807 \\
\hline 35 & 1.123 & 144.30 & 9.6237 & 5.5339 & 3.9413 \\
\hline 36 & 1.097 & 129.65 & 9.6329 & 5.5622 & 3.9685 \\
\hline 37 & 1.071 & 114.36 & 9.6422 & 5.6450 & 4.0163 \\
\hline 38 & 1.045 & 102.13 & 9.6512 & 5.5540 & 3.9455 \\
\hline 39 & 1.020 & 93.480 & 9.6541 & 5.4849 & 3.8996 \\
\hline 40 & 0.996 & 87.236 & 9.6428 & 5.5140 & 3.8899 \\
\hline 41 & 0.972 & 82.877 & 9.6317 & 5.2317 & 3.6973 \\
\hline 42 & 0.950 & 79.058 & 9.6361 & 7.7636 & 5.4683 \\
\hline 43 & 0.910 & 75.664 & 9.6589 & 9.4923 & 6.6504 \\
\hline 44 & 0.850 & 74.599 & 9.6911 & 10.201 & 7.1011 \\
\hline 45 & 0.780 & 79.212 & 9.7591 & 12.097 & 8.3351 \\
\hline 46 & 0.625 & 94.853 & 9.9317 & 12.212 & 8.2745 \\
\hline 47 & 0.500 & 125.65 & 9.8992 & 12.283 & 8.1709 \\
\hline 48 & 0.400 & 170.83 & 9.9640 & 11.161 & 7.3494 \\
\hline 49 & 0.350 & 212.21 & 10.006 & 9.6537 & 6.3468 \\
\hline 50 & 0.320 & 239.14 & 10.037 & 8.0837 & 5.3218 \\
\hline 51 & 0.300 & 25.238 & 10.0065 & 8.2297 & 5.4283 \\
\hline 52 & 0.280 & 25.102 & 10.103 & 10.095 & 6.6648 \\
\hline 53 & 0.250 & 236.48 & 10.179 & 10.371 & 6.8318 \\
\hline 54 & 0.220 & 227.06 & 10.276 & 11.596 & 7.6010 \\
\hline 55 & 0.180 & 239.27 & 10.381 & 12.016 & 7.7886 \\
\hline 56 & 0.140 & 278.95 & 10.538 & 12.487 & 8.0119 \\
\hline 57 & 0.100 & 330.28 & 10.710 & 11.110 & 7.0761 \\
\hline 58 & 0.080 & 374.23 & 10.843 & 9.8740 & 6.2623 \\
\hline 59 & 0.067 & 413.25 & 10.958 & 8.5780 & 5.4284 \\
\hline 60 & 0.058 & 451.67 & 11.056 & 8.3389 & 5.2650 \\
\hline 61 & 0.050 & 497.09 & 11.152 & 8.6543 & 4.4503 \\
\hline 62 & 0.042 & 551.57 & 11.370 & 8.5157 & 5.3526 \\
\hline 63 & 0.035 & 607.68 & 11.643 & 7.4212 & 4.6604 \\
\hline 64 & 0.030 & 667.32 & 11.886 & 7.8852 & 4.9441 \\
\hline 65 & 0.025 & 745.52 & 12.159 & 8.3875 & 5.2502 \\
\hline 66 & 0.020 & 854.78 & 12.521 & 8.9734 & 5.6058 \\
\hline 67 & 0.015 & 1022.6 & 13.056 & 9.6824 & 6.0312 \\
\hline 68 & 0.010 & 1333.1 & 14.183 & 10.749 & 6.6879 \\
\hline 69 & 0.005 & 2231.1 & 17.547 & 12.002 & 7.4511 \\
\hline
\end{tabular}

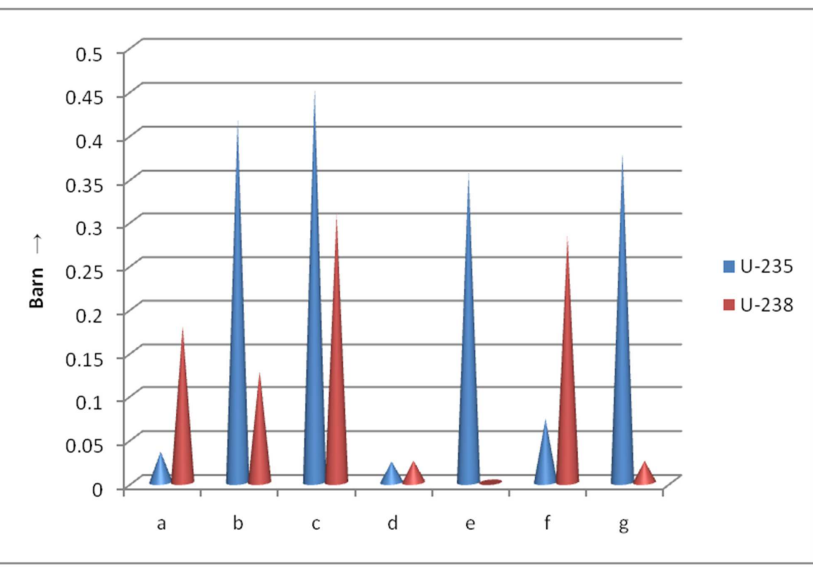

Figure 5. Cross-section of U-235 \& U-238 for BAPL-2 lattice.

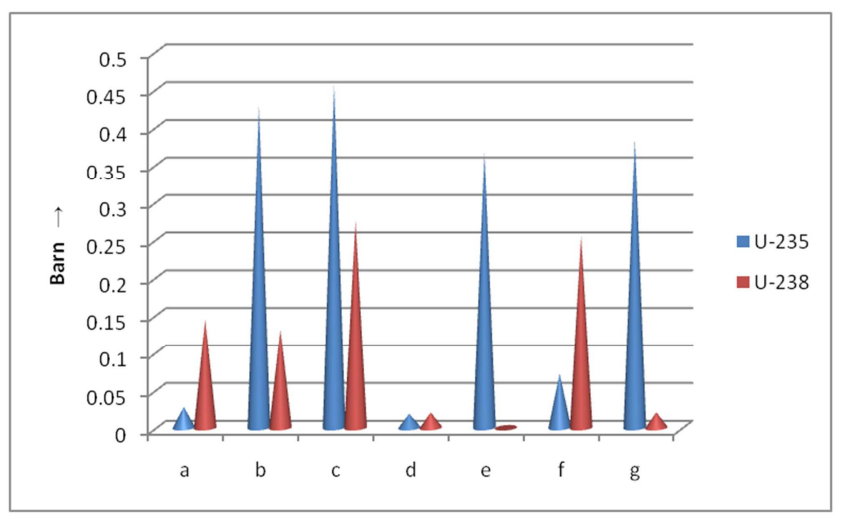

Figure 6. Cross-section of U-235 \& U-238 for BAPL-3 lattice.

Table 6. $k_{\text {eff }}$ comparison of TRX benchmark lattices.

\begin{tabular}{llll}
\hline Lattices & JEFF-3.1.2 & $\begin{array}{l}\text { Experiment } \\
\text { (CSEWG, 1986) }\end{array}$ & $\begin{array}{l}\text { Percentage of } \\
\text { error }\end{array}$ \\
\hline TRX-1 & 0.9853975 & 1.0000 & 1.46 \\
TRX-2 & 0.9826511 & 1.0000 & 1.7 \\
\hline
\end{tabular}

Table 7. $k_{\text {eff }}$ comparison of BAPL benchmark lattices.

\begin{tabular}{llll}
\hline Lattices & JEFF-3.1.2 & $\begin{array}{l}\text { Experiment } \\
\text { (CSEWG, 1986) }\end{array}$ & $\begin{array}{l}\text { Percentage of } \\
\text { error }\end{array}$ \\
\hline BAPL-1 & 0.9828444 & 1.0000 & 1.7 \\
BAPL-2 & 0.9849318 & 1.0000 & 1.5 \\
BAPL-3 & 0.987897 & 1.0000 & 1.21 \\
\hline
\end{tabular}

Table 8. Integral parameter comparison of TRX benchmark lattices.

\begin{tabular}{lllll}
\hline Lattices & $\begin{array}{l}\text { Integral } \\
\text { Parameter }\end{array}$ & $\begin{array}{l}\text { JEFF- } \\
\mathbf{3 . 1 . 2}\end{array}$ & $\begin{array}{l}\text { Experiment } \\
\text { (CSEWG, 1986) }\end{array}$ & $\begin{array}{l}\text { Percentage of } \\
\text { error }\end{array}$ \\
\hline \multirow{4}{*}{ TRX-1 } & $\rho^{28}$ & 1.3466 & 1.3200 & 2 \\
& $\delta^{25}$ & 0.0958 & 0.0987 & 2.9 \\
& $\delta^{28}$ & 0.0949 & 0.0946 & 0.31 \\
& $\mathrm{C}^{*}$ & 0.78848 & 0.7970 & 1.06 \\
& $\rho^{28}$ & 0.832 & 0.8370 & 0.59 \\
$\mathrm{TRX}-2$ & $\delta^{25}$ & 0.05868 & 0.0614 & 4.4 \\
& $\delta^{28}$ & 0.0685 & 0.0693 & 1.1 \\
& $\mathrm{C}^{*}$ & 0.6322 & 0.6470 & 2.2 \\
\hline
\end{tabular}

Table 9. Integral parameter comparison of BAPL benchmark lattices.

\begin{tabular}{lllll}
\hline Lattices & $\begin{array}{l}\text { Integral } \\
\text { parameters }\end{array}$ & $\begin{array}{l}\text { JEFF- } \\
\mathbf{3 . 1 . 2}\end{array}$ & $\begin{array}{l}\text { Experiment } \\
\text { (CSEWG, 1986) }\end{array}$ & $\begin{array}{l}\text { Percentage of } \\
\text { error }\end{array}$ \\
\hline \multirow{6}{*}{ BAPL-1 } & $\rho^{28}$ & 1.4767 & 1.3900 & 6 \\
& $\delta^{25}$ & 0.0811 & 0.08400 & 3.4 \\
& $\delta^{28}$ & 0.7540 & 0.0780 & 3.3 \\
& $\mathrm{C}^{*}$ & 0.8250 & $\ldots \ldots$ & $\ldots$. \\
& $\rho^{28}$ & 1.2101 & 1.1200 & 8.5 \\
BAPL-2 & $\delta^{25}$ & 0.0661 & 0.0680 & 2.7 \\
& $\delta^{28}$ & 0.0649 & 0.0700 & 7.2 \\
& $C^{*}$ & 0.7460 & $\ldots$. & $\ldots$. \\
BAPL-3 & $\rho^{28}$ & 0.9440 & 0.9606 & 1.7 \\
& $\delta^{25}$ & 0.0507 & 0.0520 & 2.3 \\
& $\delta^{28}$ & 0.0533 & 0.0570 & 6.4 \\
& $C^{*}$ & 0.6616 & $\ldots$ & $\ldots$. \\
\hline
\end{tabular}

\section{Discussion}

Very recent, only the integral parameters of TRX and BAPL lattices of JEFF-3.1.1 have been compared and the values of $\mathrm{k}_{\text {eff }}$ are very close to the experiment [22]. In the present work NJOY output for the two isotopes U-235 and 
U-238 the group constants are consistent with each other. For each TRX and BAPL lattices the total absorption crosssection of U-235 is larger than that of U-238, epi-thermal fission cross-section of U-238 is marginal, but the thermal fission is completely absent. The captured cross-sections of U-235 are very low but thermal fission cross-section of U235 is remarkably high. Captured cross-section of U-235 is very much lower than that of U-238. Moreover, the character cross-sections for each lattice are identical. From Tables 6 \& Table 7 , the calculated values of effective multiplication factor $k_{\text {eff }}$ are very close to the experimental values, the maximum deviation is $1.7 \%$ for TRX-2 and BAPL-1 lattices. From Tables $8 \&$ Table 9 it can be seen that the uncertainties of calculated values of the integral parameters of $\rho^{28}, \delta^{25}, \delta^{28}$ and $\mathrm{C}^{*}$ for TRX-1 \& TRX-2 lattices do not deviate by more than $5 \%$ from the experimental values. Only the values of $\rho^{28}$ in BAPL-1 and BAPL-2 lattices, values of $\delta^{28}$ in BAPL-2 and BAPL-3 show more than 5\% inaccuracy but rest of the values of the integral parameters are very close to the benchmark values.

\section{Conclusion}

This theoretical study compares with the benchmark integral parameters of thermal reactor metallic uranium (TRX) and uranium oxide (BAPL) lattices with the nuclear data library JEFF-3.1.2 by using NJOY'99.0 and WIMSD-5B codes. The results from these computations are compared with experimental values by CSEWG, and it is found that there are no significant differences between calculated and experimental values. The cross-sections for epithermal and thermal neutrons at each lattice are practically identical. The integral parameters are almost equal to the experimental values, except for few values.

In the experimental result by CSEWG, the values of $\mathrm{C}^{*}$ are present in TRX lattice but absent for BAPL lattice, therefore judgment for value of $\mathrm{C}^{*}$ for BAPL benchmark lattice are not achievable. To conclude, this analysis provides a clear confirmation of the nuclear data library JEFF-3.1.2 for the neutronic calculation of TRIGA mark-II research reactor. Therefore JEFF-3.1.2 is completely reliable for safety analysis of the TRIGA reactor at AERE, Dhaka, Bangladesh.

\section{References}

[1] M. B. Chadwick, et al., "ENDF/B-VII.0: Next generation evaluated nuclear data library for nuclear science and technology", Nuclear Data Sheets, vol. 107, pp. 2931-3060, December, 2006.

[2] O. Allaoui, et al., "Validation of ENDF/B-VII.0 nuclear data library for shielding calculations using the Monte Carlo method", International Journal of Advanced Research, vol. 2, pp. 55-62, 2014.

[3] Cross Sections Evaluation Working Group, "ENDF-6 Formats Manual", BNL-90365-2009, Brookhaven National Laboratory, pp. 1-13, 2009.
[4] R. E. MacFarlane and D. W. Muir, "NJOY99.0: Code system for producing point-wise and multi-group neutron and photon cross sections from ENDF/B", RSICC Code Package PSR480. Los Alamos National Laboratory, Los Alamos, New Mexico, USA, 1999.

[5] A. J. Koning, et al., "Status of the JEFF nuclear data library", Journal of the Korean Physical Society, vol. 59, pp. 1057-1062, August 2011.

[6] K. Shibata, et al., "JENDL-4.0: A new library for nuclear science and engineering", Journal of Nuclear Science and Technology, vol. 48, pp. 1-30, 2011.

[7] Z. Youxiang, L. Tingjin, Z. Jingshang and L. Ping, "CENDL3- Chinese evaluated nuclear data library, version 3", Journal of Nuclear Science and Technology, vol. 39, pp. 37-39, 2002.

[8] ENDF-B/V-VI: The US Evaluated Nuclear Data Library, BNL-NCS-60496, Brookhaven National Laboratory, 1993.

[9] BROND-2. Library of recommended evaluated neutron data, VANT, Ser. Nucl. Const, N 2-3.13, 1991.

[10] A. J. Koning et al., "The JEFF evaluated nuclear data project", Proceedings of the International Conference on Nuclear Data for Science and Technology, ND2007, Nice, France, 22-27 April 2007.

[11] A. Santamarina, D. Bernard and Y. Rugama, "Validation Results from JEF-2.2 to JEFF-3.1.1”, JEFF Report 22, 2009.

[12] J. R. Askew, F. J. Fayers and P. B. Kemshell, "A general description of the lattice code WIMS", Journal of the British Nuclear Energy Society, vol. 5, pp. 564, 1966.

[13] T. Kulikowska, "WIMSD-5B: A neutronic code for standard lattice physics analysis", Distributed by NEA Data Bank. Saclay, France, 1996.

[14] F. Leszczynski, "Description of Wims Library Update Project (WLUP)", 2002 International Meeting on Reduced Enrichment for Research and Test Reactors, Bariloche, Argentina, November 3-8, 2002.

[15] J. Hardy, Jr. D. Klein and J. J. Volpe, "A study of physics parameters in several water-moderated lattices of slightly enriched and natural uranium", Nuclear Science and Engineering, vol. 40, pp. 101-115, 1970.

[16] R. L. Hellens and G. A. Price, "Reactor physics data for watermoderated lattices of slightly enriched uranium", Reactor Technology Selected Reviews-1964, 529.

[17] J. R Brown, D. R. Harris, F. S. Frantz, J. J Volpe, J. C. Andrews and B. H. Noordhoff, Kinetics and buckling measurements in lattices of slightly enriched $\mathrm{U}$ or $\mathrm{UO}_{2}$ rods in $\mathrm{H}_{2} \mathrm{O}$. WAPD-176, January, 1958.

[18] M. Halder and S. M. T. Islam, "Comparative study of generated wimsd-5b multi-group constants library based on JENDL-3.2 with JEFF-3.1.1 CENDL-3.0 and original WIMS and validation of generated library through some benchmark experiments analysis", IOSR Journal of Applied Physics, vol. 8, pp. 39-43, 2016.

[19] M. N. Uddin, M. M. Sarker, M. J. H. Khan and S. M. A. Islam, "Validation of CENDL and JEFF evaluated nuclear data files for TRIGA calculations through the analysis of integral parameters of TRX and BAPL benchmark lattices of thermal reactors", Annals of Nuclear Energy, vol. 36, pp. 1521-1526, 2009. 
[20] R. Sher and S. Fiarman, "Studies of Thermal Reactor Benchmark Data Interpretation: Experimental Corrections", EPRI NP-209, US, October 1976

[21] Cross Section Evaluation Working Group (CSEWG), "Benchmark specifications with supplements", Brookhaven National Laboratory, National Nuclear Data Center, Upton, New York 11973, BNL-19302, II. ENDF-202, USA, November, 1986.
[22] K. Benaalilou, et al., "A comparative study of integral parameters for TRX and BAPL benchmark lattices of thermal reactors for neutronics analysis of TRIGA MARK-II research reactor at CNESTEN using the cross-section ENDB-VII and JEFF3.1", International Journal of Current Research, vol. 6, pp. 4519-4523, 2014. 